\title{
Relationship Between Best Practice And Integrated Supply Networks
}

Graeme D. Sheather (E-mail: grameme.sheather@uts.edu.au), University of Technology, Sydney, Australia

\begin{abstract}
This paper reports on an empirical study to examine the relationship between supply chain performance and its impact on firm performance - a controversial issue in the literature. It develops an integrated performance measurement framework to survey the relationship between best practice firms and their position in supply/buy networks operating between firms in the Electronics and IT Communications industry in the Northern Adelaide Region of South Australia. The methodology joins models of best practice with theories of structural network analysis applied to a sample of 44 original equipment manufacturers (OEMs) and their first tier suppliers and customer firms. It uses a combination of quantitative and qualitative analysis to arrive at a classification of best practice firms, and correlates their leader and lagger status against a five class typology of supply and buy networks for the OEM firm, to show the impact of supply chain performance on firm performance. The results reported here are a pilot study to test the validity of the conceptual framework preparatory to a future survey of the full population of firms in the industry operating multi-tier supply/buy chains. Advanced statistical techniques and snowball sampling will be used to test and confirm the preliminary relationships presented here. The study was sponsored by Playford City Council as part of its Industrial Renewal Program for Northern Adelaide to build regional systems of innovation and agendas for change.
\end{abstract}

\section{Introduction: The global context of supply chain management}

Global marketplace competition requires Australian businesses to be innovative, adaptive, agile and able to achieve world class performance in product and service delivery, now that earlier expectations of quality and value for money have been eclipsed by time-based competition. To meet these demands for customization, speed, and agility, organisations focus on their core business; outsourcing marginal activities; entering networks and forming strategic alliances; participating in global supply chains and finally, eliminating the traditional boundaries between customers and producers. These advances are accelerating productivity and supply chain integration, to the extent that distribution bottlenecks are as feared today as bottlenecks in production were just ten years ago. Efficiency in the logistics of global and inter-regional supply chains is the key to successful time-based competition where services and products are demanded in "markets of one", in "zero time", and with the shift of supply chains to "virtual value "webs"(Andrews and Hahn, 1998). These pressures and the globalization drivers of market participation, cost control, technology enhancement, government regulation, and global competitive strategy, are forcing the adoption of an integrated supply chain management approach.

In response to these challenges, there is a dearth of empirical evidence about how the operational characteristics of integrated supply/buy networks and their management, impact corporate performance (Shankar, 2001) - the recent work of Harrison (2000), De Meyer and Kim (1998), and Gilmour et al (1999) for Australian SMEs, being exceptions. In dispute are the appropriate performance measures, the principles and structural intuition underlying their operation, and robust theoretical models to guide empirical research (Kiefer and Novack, 1999). The rhetoric on 'how to' manage is largely prescriptive (see for example Handfield and Nichols, 1999) or based on individual case studies and anecdotal evidence (DIST, 1997; IQPC, 1997). To redeem this situation requires an understanding of the mechanisms underlying organisational performance in complex supply/buy networks operating in global marketplaces. Supply chain management presents a number of new challenges for researchers and managers in logistics faced with integrating cross-functional processes, technological and organisational capabilities, 
enabled by new information technologies (Skeoett-Larsen, 1999). For Wisner and Tan (2000:33) the concept of integrated supply chain management..."Is still evolving. There is no generally accepted definition of supply chain management or general understanding of how supply chain management impacts organisational characteristics and practices"... or how it affects competitive capability. This need to take a strategic perspective for linking supplier performance to firm performance has also been advocated by Bechtel and Jayaram (1997).

This paper reports on a Step 1 pilot study to explore the situation amongst a group of Australian SMEs operating in the Electronics and IT Communications industry in the Northern Adelaide Region of South Australia. The study uses empirical evidence from a survey of 44 OEMs to test the utility of an 'integrated performance measurement methodology' to advance our understanding of the relationship between supply chain performance and its impact on competitive capability and firm performance. Part One illustrates how a best practice model scorecard is used to differentiate between 'leader' and 'lagger' firm performance. Part Two shows how the underlying complexity inherent in the procurement and customer networks of these OEMs can be progressively decomposed into a hierarchy of 'industry lattices', 'procurement webs' and finally supply/buy 'trees' using cluster analysis and graph layout software. Part Three demonstrates how these relationships are interpreted according to the principles of structural network analysis to arrive at a taxonomy of supply/buy networks. The final section of the paper presents the results as a matrix that classifies the 44 OEM firms by best practice status by category of supply/buy network, illustrating the impact of supply chain structures and characteristics on business performance for the Electronics and IT Communications industry.

\section{Study Framework and Methodology}

The conceptual framework adopted for the study of best practice firms and the structure of their supply chain and procurement networks, compares the effectiveness of 'strategic facilitators and decision making practices' employed by a firm to leverage its 'competitive capability and operational outcomes', and relates these to the intensity of its 'network of supplier/buyer transactions' and resulting levels of 'business performance'. The performance measurement framework is shown in Figure 1. On one side of this model the 'practices' and 'outcomes' index is combined to produce a 'site capability scorecard'. This dimension of the model is similar to that used to gather empirical evidence on best practice organisational performance of Australian SMEs, reported in The Australian Manufacturing Council's two studies Leading the Way (AMC, 1994) and Reinventing Competitiveness (Rimmer et al, 1996). The extensive range of government and peak body studies addressing the issues of best practice and benchmarking between 1994 and 1997, also confirms the utility of such a methodology (DIST, 1997). The expansion of the Best Practice framework to include the dimension of 'supplier/buyer transactions' as a 'supply chain scorecard', is an innovation introduced by this study. The logic builds upon the work of De Meyer and Kim (1997) to conceptualize the structure of integrated supply chains, Harrison's (2000:1) taxonomy of "integrated supply chain management" practices" as they affect manufacturing business unit performance, and Tan et al's (1998) evidence of how supplier performance affects firm performance.

The study methodology follows the steps of the conceptual framework described above, employing analytical techniques relevant to models of best practice and theories of structural network analysis. For the "best practice scorecard', the Outcomes Index was constructed from competitive capability and business performance measures, whilst the Practice Index recorded initiatives in technology and management programs. Linear regression determines the line of best fit between the dependent variable 'outcomes' against the independent variable 'practices', identifying 'leader' and 'lagger' categories of firms/sites with high levels of business performance and best management practice as a Site Capability Scorecard. 


\section{Figure 1 Integrated Supply Chain Performance Model}

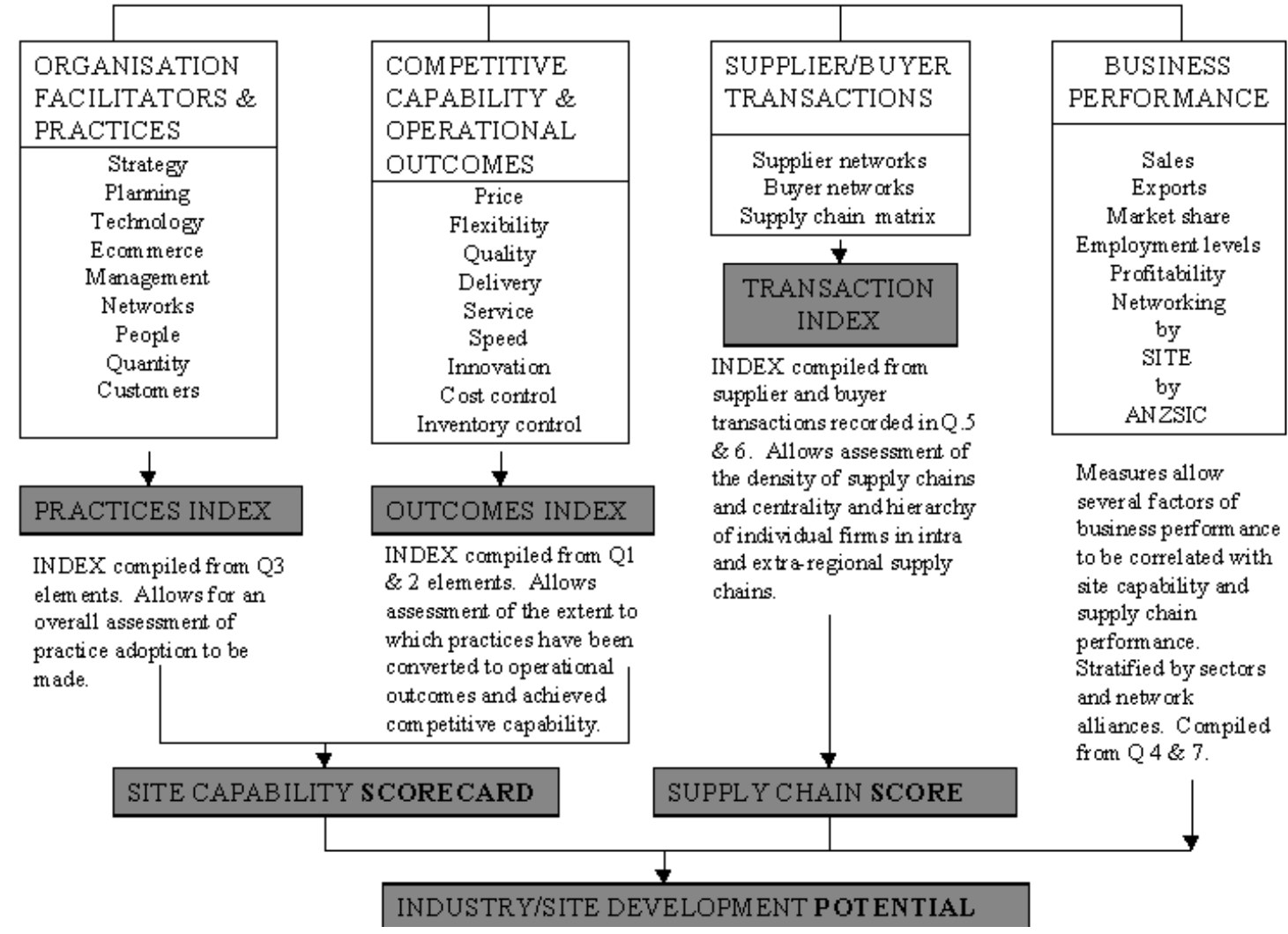

On the other side of the schema, a 'transaction index' of supplier/buyer exchanges is compiled to produce a Supply Chain Score, reflecting the intensity of transactions between the OEM and its suppliers and buyers, and the potential ability of a firm to command the centre of its respective supply/buy networks to its competitive advantage. Spatial mapping of these supply/buy networks (using vector diagrams (Krackhardt et al, 1994 and 1995) and structural network typologies based on social network analysis (Burt, 1991) was used to decompose and graph the hierarchy of interconnectedness between firms. The pattern of relationships between firms in these supply/buy networks is extremely complex, and can be expected to take a number of forms according to the literatures on structural network analysis (Doreian, 1980; Marsden, 1990; Burt, 1982; Wassermann and Faust, 1994), and the role of strategic alliances in supply chains (Spekman and Sawhney, 1995; Lomi and Grandi, 1997). A typology, using the five principles of structural network analysis to reflect the 'degree of organised integration' within the industries' supply/buy networks, formed the basis of the Supply Chain Scores. The final measure of Industry/Site Development Potential is presented as a matrix arraying sites by Best Practice status against category of Network Type.

The sample of 44 original equipment manufacturer (OEM) firms, their 143 first tier suppliers and 120 endusers and customers, was drawn from a population of "representative firms" supplied by the Engineering Employer's Association of South Australia's database. Data collection involved site visit interviews using a structured questionnaire covering competitive capability, technology and management programs, business performance, business alliances, supplier and buyer transactions, and details of company profile. The full survey instrument is available upon request. Whilst the company sites represent a selected cross section of firms within the industry, for this pilot study their responses are a 'time slice' sample indicative of best practice performance, supply/buy networks, and underlying structural relationships between firms operating in the regional Electronics and IT Communications industry. 


\section{Part One: The Best Practice Scorecard}

The Operational Practices adopted to leverage Business Performance for each of the 44 sites, are plotted to establish a measure of Site Capability in Figure 2. Top and bottom quintiles (20\% of sites) along the regression line, identify best practice 'leader' and 'lagger' firms, respectively, with the remaining firms falling within a 'midrange' performance category. The companies are listed below in Table 1, under the two categories. Mid Range sites are not listed, but can be read directly from the graph. The order is unimportant at this stage, but the key firms are clearly evident from the graph. Company names are concealed for reasons of confidentiality.

Figure 2. Best Practise: Identification of Leader \& Lagger Sites

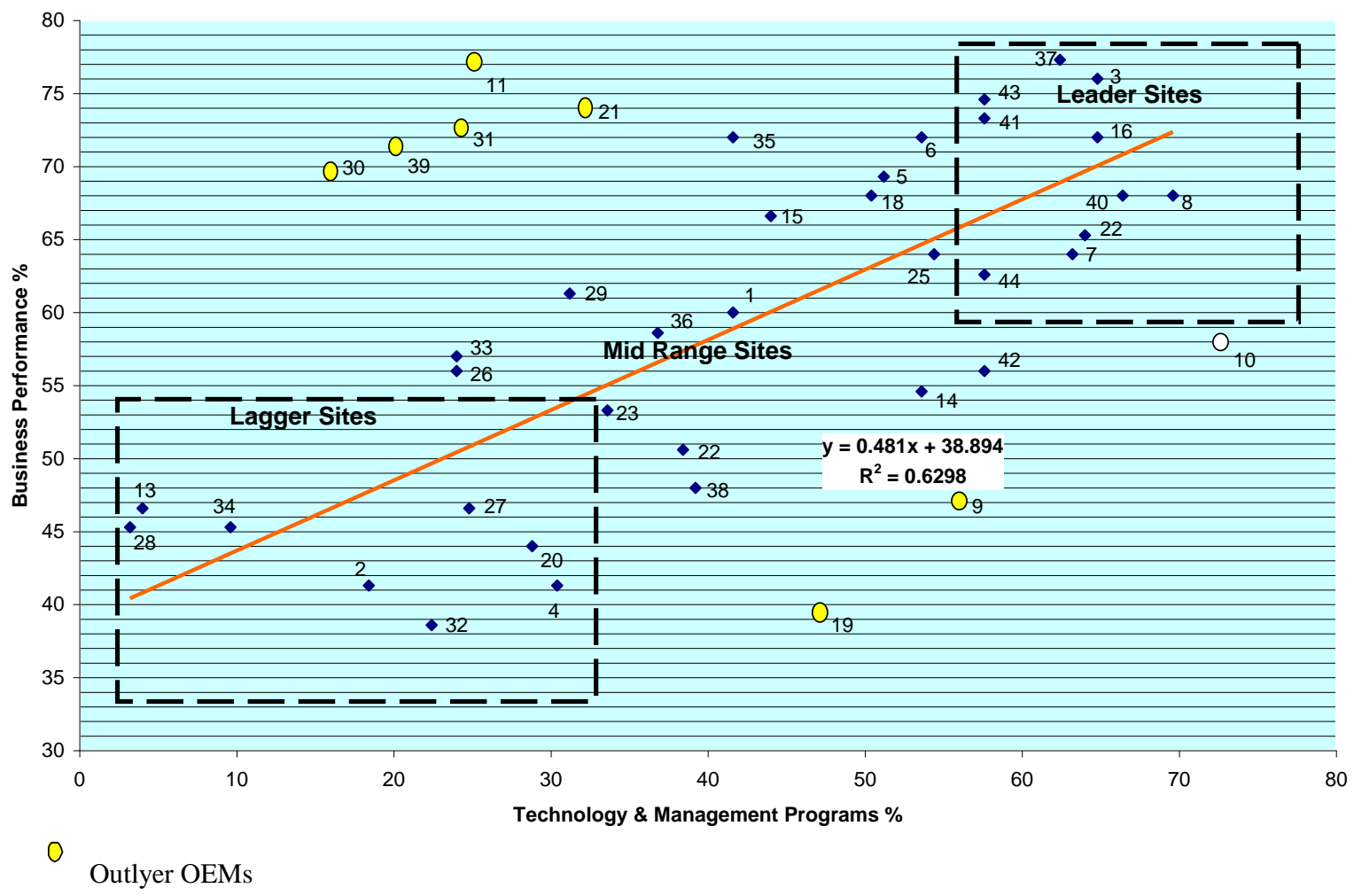

Table. 1 Best Practice Categories of OEMs

\begin{tabular}{rlll}
\multicolumn{1}{l}{ LEADERS } & Product Sector & LAGGERS & Product Sector \\
\hline Company No 37 & Electronic component & Company No 28 & Agency \\
3 & Engineering services & 13 & Agency \\
16 & PCB components & 34 & Optical systems \\
22 & Sensing systems & 2 & R and D \\
7 & Auto batteries & 32 & Elect. services \\
40 & Electrical solutions & 27 & Comm. Equipt \\
8 & Rubber products & 20 & Design services \\
41 & Visual systems & 4 & R\&D services \\
43 & Electronic component & 23 & Elect compt \\
\hline $6,18,25$ and 44 & Marginal & $24,26,33$ and 38 & Marginal
\end{tabular}


Leaders are a mix of mid (50-100 employees) to large (200 plus) firms reflecting their ability to fund investment in training and new technologies. They also have to adopt best practice and quality certification as a condition of vendor management policy with major customers, and as a requirement of entry into international markets. These firms are 'contenders' as world class manufacturers (WCMs).

Lagger firms are exclusively small (less than 15 employees) with predominantly specialized products/services, and operate as agents/brokers/marketers, and design consultants. Their need is for management and production control systems, business and basic skills training, to determine 'where to begin' before they can catch up to mid-range and leader status. At present they are at the 'back of the pack'.

Mid Range firms fall between the leader and lagger categories. These sites being close to 'best-in-class' within the industry are 'en route' to leader status. Those at the lower end of the continuum require targeted investment in continuous improvement programs to both sustain their current ranking and progress their 'contender 'status.

Marginal Sites: There are a number of firms that fall just outside the $20 \%$ quintile cut-off at both leaders and lagger levels. These firms, for all intents and purposes, display similar characteristics to their adjacent counter-part sites, and are recorded as potential leaders and laggers, below the line in the above Table 1.

Whilst there is a clear continuum of sites along the line of best fit, there are a number of 'outlyer' sites that have excellent performance achieved with minimum adoption of new technologies and practices - they are 'free riders' receiving something for nothing. There are also sites that have invested in numerous technologies, but with marginal results in performance that can be classed as 'promising', awaiting the benefits of 'experience curve' and delayed 'lag effect' of implementation, to kick in. As a result, the proportion of variation in 'Outcomes' $(46.5 \%)$ is only partially explained by 'Practices' $\left(\mathrm{y}=0.2946 \mathrm{x}+47.884\right.$ with $\left.\mathrm{R}^{2}=0.2159\right)$ due to these 'outlyer' cases, where factors other than technology and management practices explain performance. To test the robustness of the relationship a sensitivity analysis was conducted. It removed sites where explanations for exceptional business performance (due to short-term/one-off results) and/or factors such as reliance on legacy systems, delayed 'experience curve' effects of skills training, lag effects of new investments, and labour/capital intensive ratios for 'low-tech' service/consulting firms, could bias the basic relationships. These data were interpreted from qualitative responses in the survey. A reduced data set of 36 firms produced a regression equation of $y=0.481 x+38.894$ with $\mathrm{R}^{2}=0.6298(\mathrm{r}=79.4 \%)$, significantly strengthening the argument for a strong correlation between outcomes and practices.

In either case, the sensitivity analysis demonstrates the significance of best practice models to differentiate firm performance and indicate areas for continuous improvement, as past experience with best practice programs also confirms (IBM, 1998, QMI, 2003). For example, firms lying at the lower 'practices' end of the graph need to identify what factors have constrained/limited capital expenditure in technology, for example. Whilst Mid Range firms need to research and invest in improvement programs to sustain and advance their position, and 'free rider' firms analyze their business performance to ensure they can 'go the distance' in the future.

\section{Part Two: Industry structure of supply/buy chains}

This section explores the industry structure of supply/buy transactions to build the Supply Chain Score amongst the 44 OEMs and their 143 first tier supply firms and 120 end-users. Companies in the survey reflect the size and age structure of the industry with 70 percent small (less than 10), 16 percent SMEs (25-100), and 14 percent large (greater than 100) employers. Twenty percent are established and eighty percent recently established operations. At the 2 digit ANZSIC code level they are predominantly 'Other machinery and equipment' (including electronics and electrical), 'Other manufacturing' and 'Other not specified' (e.g., computing, IT, communications) sectors, with 'Fabricated metal products' completing the major categories of business enterprise. Characteristic of such specialized and customized industries, there are a wide range of service providers, agents/brokers, design consultants and computing software development houses. Importers and wholesaling agents provide the integration 
and supply chain linkages necessary for the competitive success of the sophisticated high tech electronic industry clusters of the region.

In any supply/buy network, end parts may not be finished goods within the product or category range, so end-users in a large number of instances will be customers procuring sub-assemblies or fabricated or manufactured parts to be used in finished goods to the end customer. Enterprises operating in a specific industry supply/production/distribution network will usually draw upon or distribute goods/services from across a mix of 'upstream', 'midstream', and 'down stream' industries. It is obvious that 'intermediate tier' companies will usually supply or source from multiple OEMs, so that the map of procurement exchanges becomes a complex network, or more accurately, what we prefer to call, 'industry lattices' of supply/buy transactions operating across industry sectors and manufacturing processes. For any particular manufacturing region, this lattice will also incorporate local, out-of-region and international vendors and customers.

Vector diagrams show the level of complexity inherent in these 'industry lattices', based on procurement transactions between the 44 OEM firms and their 143 suppliers recorded in Figure 3. The corresponding lattice of sales to 120 end-user companies is plotted in Figure 4. These industry lattices clearly demonstrate the complexity of the procurement logistics for the industry, despite being only a sample of firms operating within the region. A two-stage data reduction process, using vector mapping and cluster analysis techniques to extract the hierarchical structure of the logistics networks embedded in these industry lattices, is presented in the following two sections.

\subsection{Hierarchical structure of supply/buy networks}

The industry lattices were decomposed using a combination of cluster analysis and graph layout software (Krackhardt, 1995), in two steps. Step 1 examined the logistics networks operating between the OEMs and their 1st tier suppliers for evidence of multiple and single supply chain linkages. Multiple linkages identify suppliers that offer a wide range of products (either standard or specialized) to more than one OEM. Single linkages depict suppliers that provide a mix of preferred/customized product sets, and/or substitute options, to only one or two OEMs. Cluster analysis employing a similarity measure (number and pattern of linkages to common suppliers), distinguished groups of OEMs according to their multiple or single supplier 'procurement webs'. Appendix A records the 10 clusters of OEMs. The distinction according to category of top ranked Leader and Lagger firms is included under the Supply Chain Index measure in the summary tables presented in the final Results section of the paper.

Step 2 used vector diagrams to plot the inter-dependencies within and between these clusters and highlight the centrality of key supplier and buyer firms embedded in these 'procurement webs'. To illustrate the concept, Figure 5 (Part 1) presents the 'supply webs' for the top 20 OEMs that draw on multiple suppliers, plus transactions between other OEMs. The remaining 24 OEMs that source from single dedicated/preferred suppliers constitute Part 2 of this graph. A similar analysis was applied to the 'customer webs' of the 44 OEMs that sell to multiple customers and those companies that sell to single clients. Due to publication restrictions, Part 2 of the supply web, and both Parts 1 and 2 of the customer webs, are not shown here, but tabled at the oral presentation.

Even at this simplified level, the region is still a complex mix of supply networks and procurement webs. In order to compile the Transaction Index indicated in the study framework, a further stage decomposition used the intensity of site exchanges (recorded by frequency/value/volume of procurement transactions) to rank the top 20 percent of OEMs and their individual 'supply/buy chain trees'. 'Supply trees', with a list of their constituent member firms, for the top nine OEMs, are illustrated in Figure 6. A similar analysis identified 'customer trees' for the top nine OEMs. Again, due to limitations of space, these graphs are not shown here, but tabled at the oral presentation. 
Figure 3

Complexity Of Linkages Between 44 Oems \& 143 Suppliers

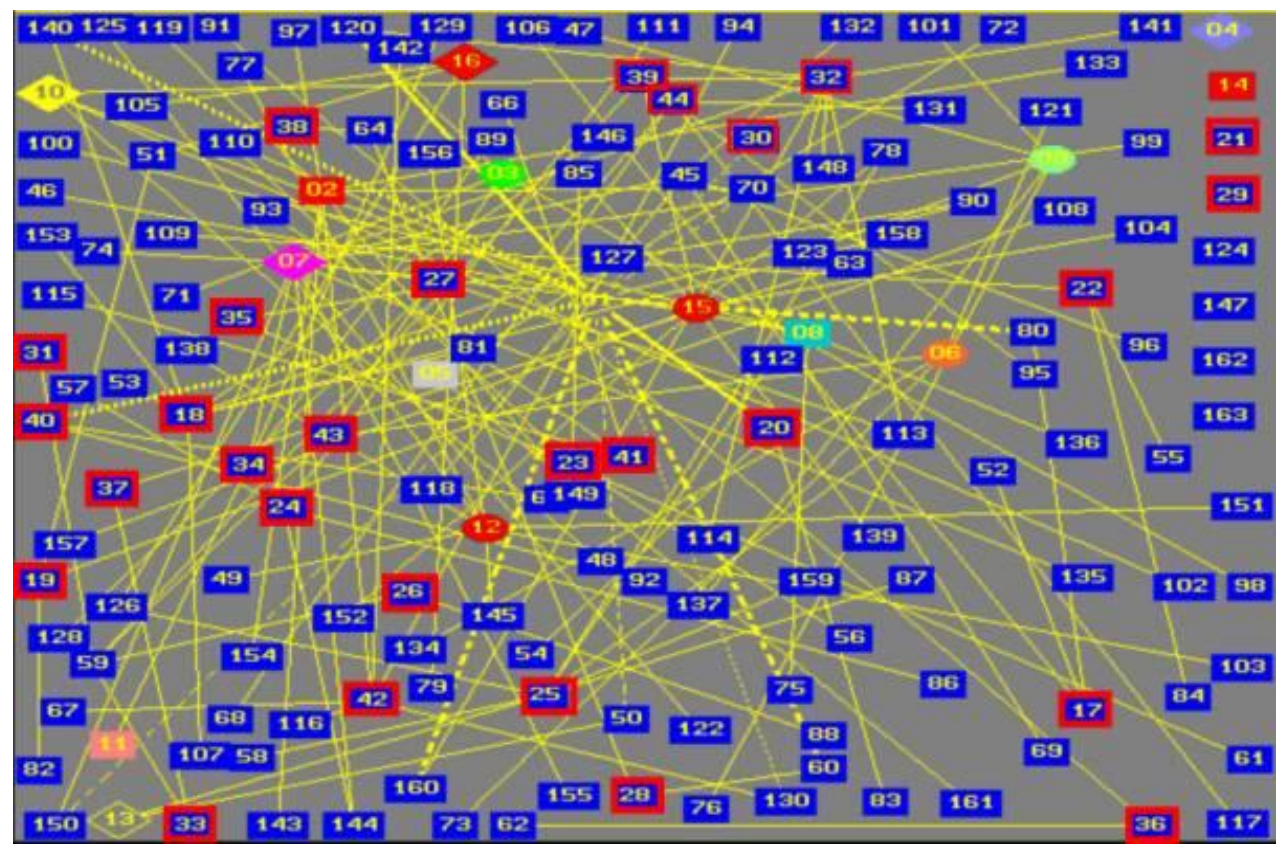

$\$ OEMs 1-16 $\square$ OEMs 17-44 $\square$ Suppliers 45-163

Figure 4

Complexity Of Linkages Between 44 Oems \& 120 Buyers

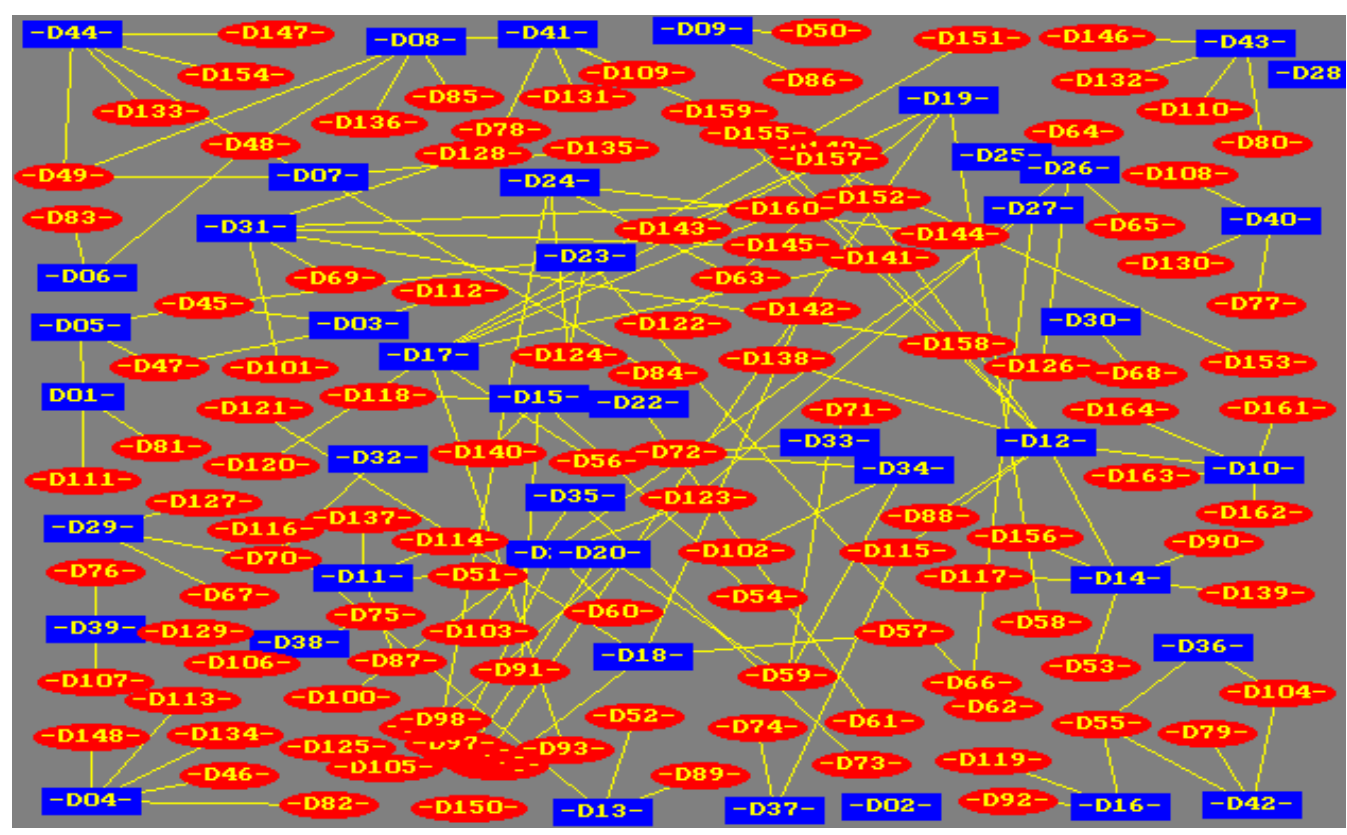

$\square$ OEMs 1-44 $\longmapsto$ Buyers 45-164 


\section{Figure 5}

Linkages Between Top 20 OEMs And Their Major Suppliers

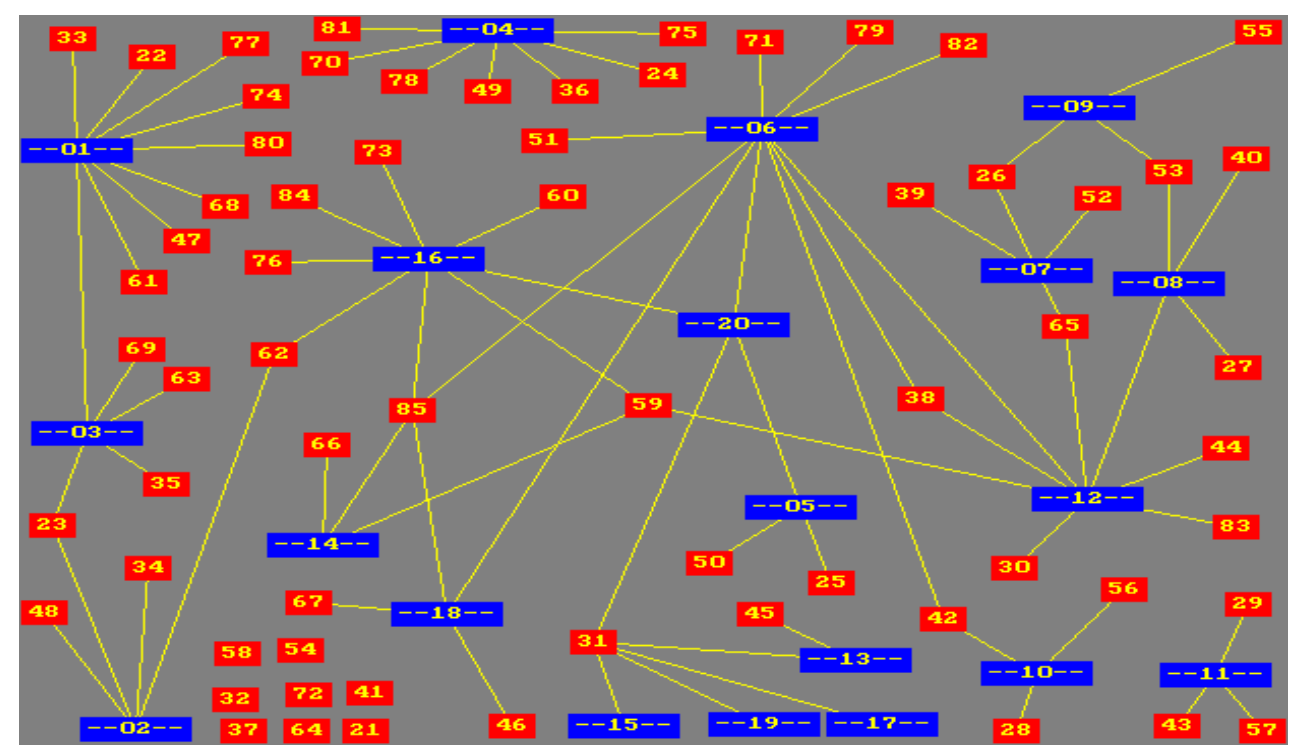

OEMs 1-20 defined by multiple linkages

Suppliers 1-82 
Figure 6

Top 20\% Of Oems Ranked By Intensity Of Exchanges With Suppliers

\begin{tabular}{|c|c|c|c|}
\hline OEM Number & Product Sector & Supplier Number & Product Sector \\
\hline B01 & Moulded Plastics & \multirow{2}{*}{$\begin{array}{l}\text { B10 } 135 \\
\text { B11 } 140\end{array}$} & \multirow{2}{*}{$\begin{array}{l}\text { Moulded Plastics } \\
\text { Aeronautical }\end{array}$} \\
\hline & & & \\
\hline B02 & Batteries & \multirow{2}{*}{$\begin{array}{l}B 12100 \\
B 13600 \\
B 14150\end{array}$} & \multirow{2}{*}{$\begin{array}{l}\text { Metallurgy } \\
\text { Plastic Components } \\
\text { Electrical }\end{array}$} \\
\hline & & & \\
\hline B03 & Electrical Components & B15 225 & Connectors \\
\hline B04 & Electrical Components & B16 225 & Sub-Assembly \\
\hline B05 & Hydraulics & B17 150 & Fasteners \\
\hline B06 & Visual Systems & B18 300 & Connectors \\
\hline B07 & Sub-Assembly & \multirow{2}{*}{$\begin{array}{l}\text { B19 } 200 \\
\text { B20 } 100\end{array}$} & \multirow{2}{*}{$\begin{array}{l}\text { Sub-Assembly } \\
\text { Electrical Components }\end{array}$} \\
\hline & & & \\
\hline B08 & Electrical Agency & B21 200 & Electrical Components \\
\hline B09 & Automotive Systems & B22 250 & Electrical Components \\
\hline
\end{tabular}

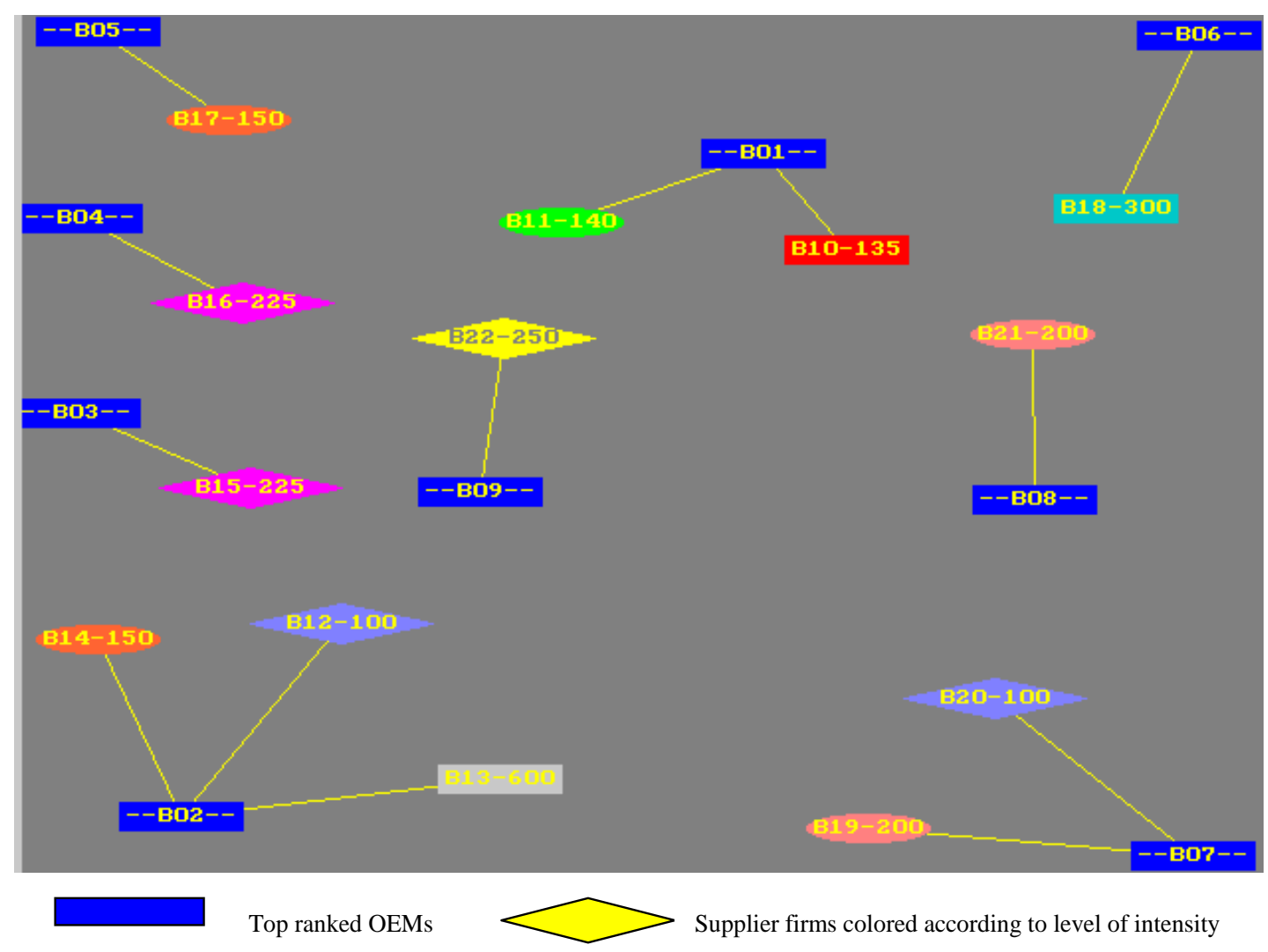




\subsubsection{Hierarchy of OEMs and Supplier Sites}

Interpretation of the hierarchy of sites was based on the structure of the above 'procurement webs' and 'supply chain trees', augmented by information contained in the survey responses. Sites with the highest intensity of supply exchanges are those supplying components, finished goods, electronic control systems and sub-assemblies to the major automotive manufacturers, plus the aircraft and marine industries. These enterprises comprise the OEM hubs of the supply/buy networks and constitute the structural base of the region's economy. Their 1st tier suppliers provide raw materials, plastics, metals, fasteners, connectors, cables, rubber, electronic parts, computer PCBs, and aircraft components for fabrication and assembly as intermediate items. Size and age of firm tends to dictate the centrality of a firm in the supply chain. A mix of smaller/younger firms closely supports these firms and small/well established firms, both supplying highly specialized and high-tech products and services. Detail characteristics and leader/lagger status of top ranked firms in these procurement webs, are recorded in Table $\mathbf{2}$ of the Results section.

\subsubsection{Hierarchy of OEMs and Buyer Sites}

Interpretation is based on the hierarchy of 'customer webs' and 'buyer trees', graphed and ranked by intensity of selling exchanges. The data showed that the pattern of sales between the OEM sites and their end-users is just as inter-dependent as the supply network. OEMs sell to each other based on tightly held contracts, but they also make multiple sales to buyers-in-common. Like the supply network, there is a predominance of 1st tier firms. Major buyers are large enterprise end-users, such as divisions of the Defense Department, Mitshibitsi, Ford, Toyota, and Lear, and retail firms in the marine, recreation, white-goods and electronics industries. Details of the top ranked firms and their leader/lagger status, are recorded in Table $\mathbf{3}$ of the Results section.

\section{Part 3: Typology of supply/buy networks}

The pattern of relationships between firms operating in these multi-level supply/buy networks could take five forms according to the principles of structural network analysis (SNA), namely, cohesion, equivalence, prominence, range and brokerage. Two of these principles depict the phenomena of structuring based on common boundaries and social bonding (namely, cohesion and equivalence), with the phenomena of network behaviour between agencies described by the principles of prominence, range and brokerage (Burt, 1991). Other scholars (see Frohlich et al, 1997) have suggested alternative conceptual frameworks as the basis of supply chain taxonomies, but none offer the rigour of the principles of structural network analysis. We have posited a taxonomy where the five structural types lie on a continuum ranging from 'disorganized' to a 'fully integrated' level of network organization. The hierarchical configuration of each type along this continuum is illustrated in Figure 7.

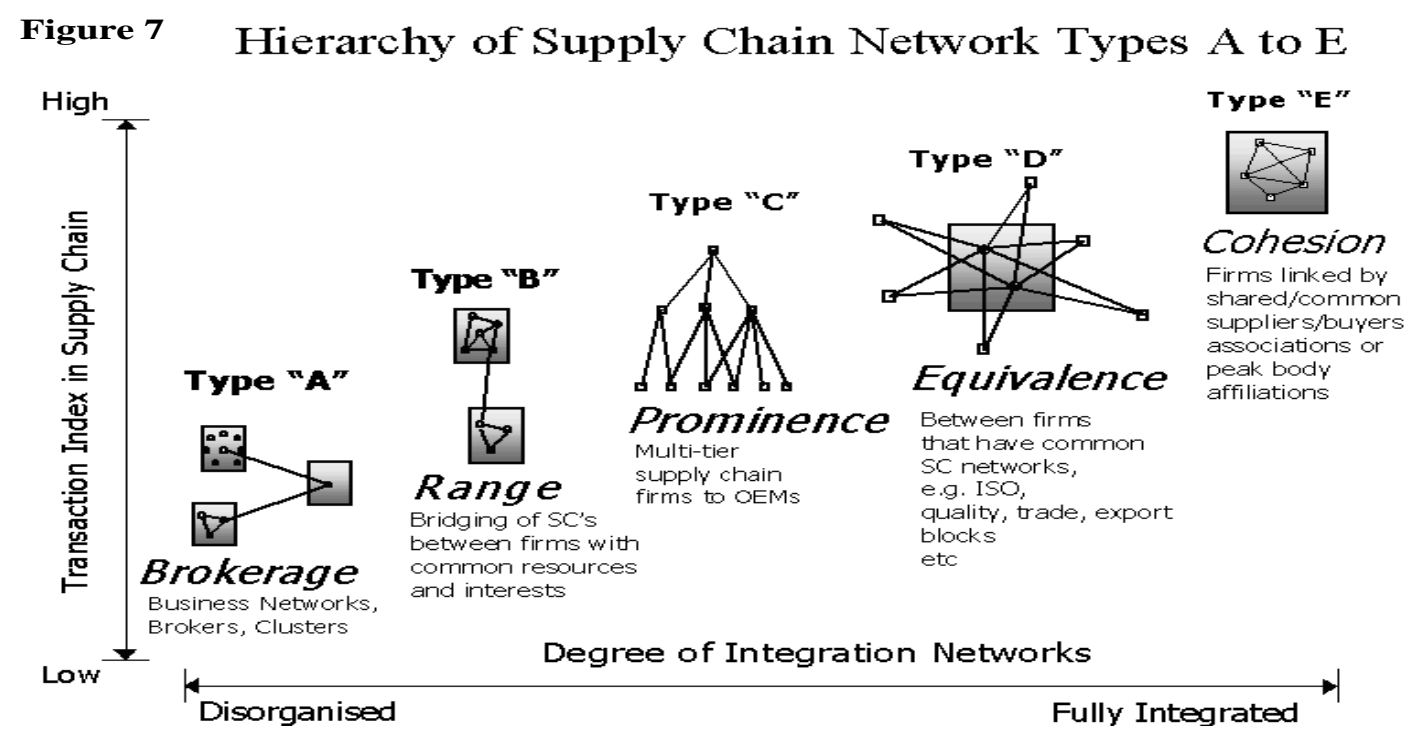


Both qualitative and quantitative techniques can be applied to test the existence of the five structural types of this taxonomy. Because of the limitations of sample size in this pilot study, an initial qualitative (Step 1) analysis was applied to the hierarchical clustering of sites and the vector diagrams to delineate groups of OEMs according to the principles of SNA supported by descriptions reported in the survey responses. Definitions of the five principles of SNA used to categorise the 44 OEM sites and their 143 first tier suppliers and 120 customers, are outlined in Appendix B. Classification involved an iterative process between: (i) pattern recognition (scanning vector diagrams in Figure 5: Parts 1 and 2, with templates of the five network configurations); (ii) confirming multiple/single linkages according to the membership of the 10 OEM groups; (iii) interpretation of the graphs, and residuals linkages, according to the five generic descriptors, and finally; (iv) clarifying key characteristics from qualitative descriptions provided in the survey responses. The structural network types are not mutually exclusive, as might be expected, and OEM firms sit across network categories, however, the following classifications can be supported.

- $\quad$ The predominant type of network linking OEMs and their 1st tier suppliers is Type $\mathrm{C}$ based on Prominence relationships. The type of 'organised integration' is hierarchical, with a large number of short procurement chains to end-user component and/or sub-assembly firms, demonstrated by the cluster groupings in Appendix B. There is a mix of multiple and single product firms, where multiple groupings predominate due to the complexity of elaborately transformed manufactures (ETMs) for the automotive and defense industries. Leader firms are driven by quality and vendor compliance demanded by end-user customers. The large number of joint C-B Types for buy chains, indicates that OEMs use the facilities of Type B 'integrators' such as design and engineering services to coordinate production, and the resources of common markets and purchase consortia, to serve extended bills of materials typical of hierarchical supply chains feeding automotive and defense end-users. Logically, multiple product range firms predominate in these markets. Larger and high-tech companies achieve Leader status, with remaining small size firms at least achieving Mid Range status due to incentives for continuous vendor improvement. There are also three multi-tier supply chains operating between the major automotive OEMs. Within these networks there is usually a key Leader firm providing the central performance guidelines for technology quality and conformance to specification, under preferred supplier contracts.

- The hierarchical categorization of supply sites revealed that a number of OEMs sell to each other, or operate as agents for common high demand products. They represent Type B Range relationships, based on the bridging of supply chains to share common resources and interests, as explained above. They tend not to participate in business or formal industry networks, countering this disadvantage through direct intercompany 'integrator' linkages for JIT, quality control, and vendor management programs.

- Due to the need for contractual agreements and ISO certification in the automotive and defense industries, there are a number of third party agents and consultant services acting as inter-firm brokers responding to market opportunities. Type A Brokerage relationships operate throughout the industry, but only one example within the top 20 percent of supplier firms, and two amongst buyer companies. The level of market 'disorganisation' inherent with this typology is corrected in the electronics and defence industries through the existence of R\&D, CSIRO and CRC institutions providing high-tech research services and informal networks to foster innovation.

- $\quad$ The breakdown of data, for firms in Figure 5, revealed a large number of OEMs draw their input of goods/services from common suppliers. These constitute Type D Equivalence networks, where the OEM firms do not have direct linkages but share common and independent resources. A number of both supply and buyer OEMs share common IT bureaux, computing and design services, joint freight forwarders, and channel agents for marketing and product promotion. At this date, however, only one of the top ranked supply OEM firms fits this category.

- At this stage of industry structuring, there is no evidence of Type E Cohesion relationships formed between firms operating in the Electronics and IT Communications industry. Type $\mathrm{E}$ is the fundamental basis for cluster formation, since firms are not only linked through common supply/buy chains, but also collaborate for export markets, form associations with peak body or government partners and build cross-sector 
strategic alliances. Only three top ranked OEMs participate in business networks, and these are independent memberships.

\section{Results of best practice analysis and network classification}

Results of this pilot study support the hypothesis that supply chain structure has a significant influence on competitive capability and firm performance. Best practice 'leader' performance is clearly linked to the firm's centrality in its supply/buy network, and the type/level of 'organised integration' inherent in these networks. The correspondence of top ranked OEM firms by best practice status with the five network types is presented as a matrix in Figure 8. It shows three distinct groups incorporating both supplier and buyer OEMs, all centered around Type $\mathrm{C}$ Prominence and Type B Range networks. Groups A and B contain Leader and Mid Range firms, whilst Group C represents typical Lagger firms.

Figure 8 - Matrix showing relationship between Best Practice Status and Network Typologies

\section{Best Practice Status}

LEADER

MID RANGE

LAGGER

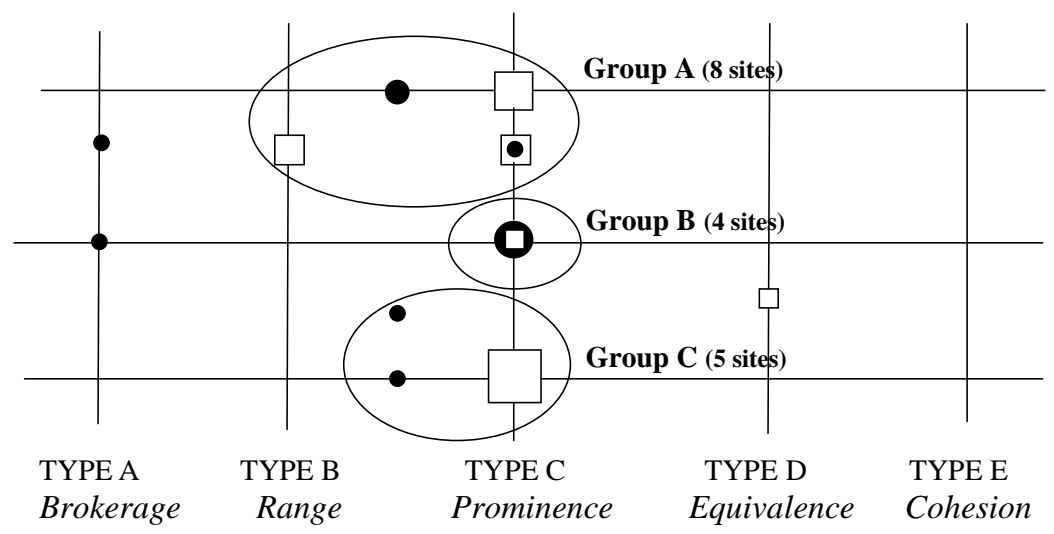

KEY NOTATIONS

Network Typologies

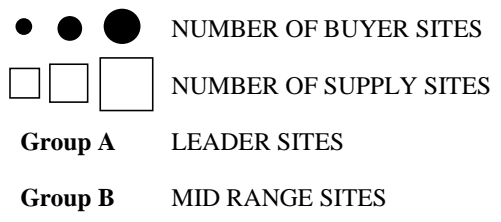

Details of the characteristics of the top ranked (by intensity) supplier QEMs and their measures on the three scorecard Indexes specified in the 'integrated supply chain performance' framework, are shown in Table 2. Corresponding characteristics and measures for the top ranked (by intensity) buyer OEMs, are shown in Table 3. For the supply networks, Leader firms predominate in OEM Groups 6,7 and 8, followed by Marginal leader and Mid range firms in Group 10. Leader and Marginal leader firms have high 'intensity' scores, multiple links to groups of common suppliers/buyers (reflecting centrality in their respective networks), and operate within almost exclusively within highly organised hierarchical Type C Prominence networks. For the buyer OEMs, there is a mix of Type C Prominence with Type B Range, and some Type A Brokerage networks operating. This is because the OEMs' customer base involves a mix of multiple and single order sales of finished products/items to a wide range of final equipment manufacturers. There are also fewer OEMs in the Lagger category, due to the pressures of maintaining best practice in highly competitive markets. 
Table. 2 - Summary characteristics of top ranked supplier OEMs

\begin{tabular}{|c|c|c|c|c|c|c|c|c|c|c|}
\hline \multirow[b]{2}{*}{$\underline{\text { Rank }}$} & \multirow[b]{2}{*}{ Coy } & \multirow{2}{*}{$\begin{array}{l}\text { Best Practice } \\
\text { Product Sector }\end{array}$} & \multirow[b]{2}{*}{$B / P$} & \multirow[b]{2}{*}{ Size } & \multirow{2}{*}{\multicolumn{2}{|c|}{ Age Net }} & \multicolumn{3}{|c|}{ Supply chain } & \multirow{2}{*}{$\begin{array}{l}\text { Network Typology } \\
\text { Classification }\end{array}$} \\
\hline & & & & & & & Linkage & Intsy & Grp & \\
\hline 1 & 7 & Auto batteries & $\mathrm{Le}$ & 257 & 36 & $\mathrm{~N}$ & Multiple & 850 & 7 & $\mathrm{C}$ \\
\hline 2 & 34 & Optical systems & $\mathrm{La}$ & 15 & 12 & $\mathrm{~N}$ & Single & 300 & 3 & $\mathrm{C}$ \\
\hline 3 & 36 & Sub-assemblies & $\mathrm{M}$ & 14 & 63 & $\mathrm{~N}$ & Single & 300 & 3 & $\mathrm{C}$ \\
\hline 4 & 6 & Molded plastics & Le/Ma & 61 & 3 & $\mathrm{Y}$ & Multiple & 275 & 10 & $\mathrm{C}$ \\
\hline 5 & 44 & Auto sub-assem & Le & 151 & 47 & $\mathrm{~N}$ & Multiple & 250 & 6 & $\mathrm{C}$ \\
\hline 6 & 12 & Electrical comp & $\mathrm{La}$ & 4 & 14 & $\mathrm{~N}$ & Single & 225 & 2 & $\mathrm{C}$ \\
\hline 7 & 23 & Electrical comp & $\mathrm{La}$ & 19 & 35 & $\mathrm{~N}$ & Single & 225 & 4 & $\mathrm{C}$ \\
\hline 8 & 42 & Electric agency & $\mathrm{Le} / \mathrm{Ma}$ & 5 & 9 & $\mathrm{~N}$ & Multiple & 200 & 8 & B \\
\hline 9 & 26 & Hydro consulty & $\mathrm{La}$ & 5 & 14 & $\mathrm{~N}$ & Multiple & 150 & 5 & $\mathrm{D}$ \\
\hline
\end{tabular}

NB: $\mathrm{B} / \mathrm{P}=$ Leader/Lagger $(\mathrm{M}=$ Mid range; $\mathrm{Ma}=$ Marginal $):$ Size $=$ Employees: Age $=$ Years: Networks = Participation Y $/ \mathrm{N}$ : Linkage $=$ Multiple/Single product portfolio: Intensity $=$ Number of transactions across all connections: Group $=$ Cluster Number 1-10: Classification $=$ Network typology A-E

Table. 3 - Summary characteristics of top ranked buyer OEMs

\begin{tabular}{|c|c|c|c|c|c|c|c|c|c|c|}
\hline Rank & Coy & $\begin{array}{l}\text { Best Practice } \\
\text { Product Sector }\end{array}$ & $B / P$ & Size & Age & $\mathrm{Net}$ & $\begin{array}{l}\text { Supply ch } \\
\text { Linkage }\end{array}$ & Intsy & Grp & $\begin{array}{l}\text { Network Typology } \\
\text { Classification }\end{array}$ \\
\hline 1 & 6 & Molded plastics & $\mathrm{Le} / \mathrm{Ma}$ & 61 & 3 & $\mathrm{Y}$ & Single & 1950 & 3 & A-C \\
\hline 2 & 44 & Auto sub-assbly & Le & 157 & 47 & $\mathrm{~N}$ & Multiple & 1350 & 7 & C-B \\
\hline 3 & 21 & Marine & $\mathrm{M}$ & 6 & 29 & $\mathrm{Y}$ & Single & 700 & 4 & $\mathrm{C}$ \\
\hline 4 & 7 & Auto batteries & Le & 257 & 36 & $\mathrm{~N}$ & Multiple & 645 & 6 & C-B \\
\hline 5 & 9 & Electrical ignitn & $\mathrm{M}$ & 120 & 17 & $\mathrm{~N}$ & Single & 450 & 3 & $\mathrm{C}$ \\
\hline$\underline{6}$ & 33 & Retail techny & $\mathrm{La} / \mathrm{Ma}$ & 18 & 13 & $\mathrm{~N}$ & Multiple & 300 & 5 & $\overline{C-B}$ \\
\hline 7 & 5 & Defence prods & $\mathrm{Le} / \mathrm{M}$ & 117 & 19 & $\mathrm{~N}$ & Single & 200 & 4 & A-C-B \\
\hline 8 & 42 & Auto electrical & $\mathrm{Le} / \mathrm{M}$ & 5 & 9 & $\mathrm{~N}$ & Multiple & 200 & 5 & C-B \\
\hline 9 & 23 & Electric comp & $\mathrm{La}$ & 14 & 35 & $\mathrm{~N}$ & Multiple & 150 & 5 & C-B \\
\hline 10 & 17 & Precision fabn & M & 32 & 24 & $\mathrm{~N}$ & Multiple & 132 & 9 & $\mathrm{C}$ \\
\hline
\end{tabular}

\section{Discussion and conclusions}

For Best Practice, there is a clear distinction between Leader, Mid Range and Lagger firms, as a measure of firm performance. The basic structure of the industry revolves around a hierarchy of industry networks, procurement webs and supply/buy trees. Analysis of these supply/buy chains based on intensity of business and procurement exchanges, identified those firms at the hubs of regional networks which act as leverage points for regional multiplier benefits to the industry.

Concerning the Typology of Networks, of the five possible types of structural networks, three were shown to operate amongst the 44 OEM companies. The most extensive Type C Prominence networks, reflect the high level of 'organised integration' in hierarchical supply/buy chains incorporating many small and/or first tier suppliers, but also the few larger OEMs that support multiple-tier supply chains. Key Leader firms tend to be at the center of these networks. Informal self-driven 'integrator' linkages produce a number of Type B Range networks facilitated by mutual selling/buying contacts. Agents, brokers, and institutional and government partnerships operate to facilitate inter-firm connections at the 'disorganized' end of the spectrum as Type A Brokerage networks. Only one incidence of a Type D Equivalence, and none of a Type E Cohesion network, was found. However, future programs of government assistance can target these two structures to help firms move towards the ultimate Type E Cohesion networks as the basis for potential industry clustering. 
The relationship between best practice firms, their centrality in supply/buy networks and level of organised integration according to supply chain typology, confirmed the posited correlation between firm performance and supply chain performance for major OEMs and their first tier suppliers and customers, operating within the Electronics and IT Communications industry in the Northern Adelaide Region. Results of this pilot study provide support for the utility of an 'integrated supply chain performance measurement' methodology to advance our understanding of the supply and buy chain networks operating within a region, and how they affect competitive capability and firm performance. We believe these results can make a contribution to the theoretical debates on the topic. Finally, the methodology was found to be sufficiently robust to form the basis for a more comprehensive analysis, using a stratified sample of the full population of enterprises with snow ball sampling of $2^{\text {nd }}$ and $3^{\text {rd }}$ tier suppliers and statistical inferences of SNA to identify the major network types operating in related regional industries. This Step 2 analysis will apply discriminant analysis and ANOA to the principles of SNA incorporated in the UCINet software package (Borgatti et al, 1999). Full acknowledgement is made to Playford City Council for its sponsorship of this pilot study as part of its Industrial Renewal Program for Northern Adelaide to build regional systems of innovation and agendas for change.

\section{References}

1. Andrews, P.P. and Hahn, J. "Transforming supply chains into value webs", Strategy and Leadership, Vol. 26, No. 3, pp 6-11, 1998.

2. AMC. Leading the Way: A study of Best Practice Management Practice in Australia and New Zealand, Australian Manufacturing Council, Melbourne, November, 1994.

3. Bechtel, C. and Jayaram, J. "Supply Chain Management: A Strategic Perspective", The International Journal of Logistics and Management, Vol. 8, No.1, pp 15-34, 1997.

4. Borgatti, S.P., Everett, M.G. and Freeman, L.C. UCINET 5.0 Version 1.00. Natick: Analytical Technologies Inc., 1999.

5. Burt, R.S. Structure: A General Purpose Network Analysis Program, New York, Columbia University, 1991.

6. $\quad$ Burt, R.S. Towards a Structural Theory of Action, New York, Academic Press, 1982.

7. De Meyer, A. and Kim, J. "Understanding Integrated Supply Chain Management (ISCM)" in Proceedings of the Fourth International Decision Science Institute Conference Incorporating the 1997 Asia-Pacific Meeting, Vol. 2, pp 594-596, Sydney, Australia, 1997.

8. $\quad$ DIST The Best Practice Experience, Volumes 1-3, Melbourne, Pitman Publishing, 1997.

9. Doreian, P. "Linear models of spatially distributed data: spatial disturbances and spatial effects?", Sociological Methods \& Research, Vol. 9, pp 29-60, 1980.

10. Frohlich, M., Dixon, J. and Arnold, P. “A Taxonomy of Supply Chain Strategies” in Proceedings of 1997 Annual Meeting, Decision Science Institute, San Diego, California, Vol.3, pp 1281-1283, 1997.

11. Gilmour, P., Harrison, N. and Moore, P. "The Role of Logistics in the Formulation and Deployment of Strategy: An Empirical Analysis of Australian Packaged Consumer Products Manufacturers" International Journal of Logistics: Research and Applications, Vol. 1, No. 3, pp 265-282, 1998.

12. Handfield, R.B. and Nichols, E.L. An Introduction to Supply Chain Management, New Jersey, Prentice Hall, 1999.

13. Harrison, N. Does the attainment of ISCM ordain MBU performance?, Research Seminar Paper, Macquarie Graduate School of Management, Macquarie University, Sydney, Australia, May, 2000.

14. IBM Pathways to Global Excellence: Incorporating the Probe Benchmarking Tool, IBM Global Services, Sydney, June, 1998.

15. IQPC "Gaining Competitive Advantage through Integrated Supply Chain Management", International Quality \& Productivity Centre Conference, 10-11 December, Wentworth Hotel, Sydney, 1997.

16. Krackhardt, D. "Graph theoretical dimension of informal organisations". In Kathleen Carley and Michael Prietula. eds, Computational Organisational Theory, Lawrence Erlbaum Associates, Inc, 1994.

17. Krackhardt, D., Blythe, J., McGrath, C. and Herbert, M. KrackPlot 3.0, User's Manual, September 22, 1995. 
18. Kiefer, A.W and Novack, R.A. "An empirical analysis of wharehouse measurement systems in the context of supply chain implementation”, Transportation Journal, 38(3) : pp 18-27, Spring, 1999.

19. Knoke, D. and Kuklinski, J.H. Network Analysis, Beverley Hills, Sage Publications 1982.

20. Lomi, A. and Grandi, A. "The Network Structure of Inter-Firm Relationships in the Southern Italian Mechanical Industry", in Ebers, M (ed) The Formation of Inter-Organizational Networks, Oxford, Oxford University Press, 1997.

21. Lummus, R.R. and Vokurka, R.J. "Defining Supply Chain Management: a Historical Perspective and Practical Guidelines”, Industrial Management \& Data Systems, 99 (1) : pp 11-17, 1999.

22. Macneil, J., Tesi, J., Cupples, J. and Rimmer, M. Benchmarking Australia: Linking Enterprises to World Best Practice, Sydney, Longman, 1994.

23. Marsden, P.V. "Network Data and Measurement", Annual Review of Sociology, Vol. 16, pp 435-463, 1990.

24. McMahon, R. "Picking Winners Amongst Manufacturing SMEs Using Data from Australia's using Longitudinal Survey", Small Enterprise Research, 8, pp 56-70, 2000.

25. Rimmer, M., Macneil, J., Chenall, R., Langfield-Smith, K. and Watts, L. Reinventing Competitiveness; Achieving Best Practice in Australia, Melbourne, Pitman.

26. Shankar, V. "Integrating Demand and Supply Chain Management", Supply Chain Management Review, 5 (5) : pp 76-82, Sept/Oct, 2001.

27. Sheather, G.D. "Re-engineering Australian Manufacturing” in Genoff, R. and Green, R., Manufacturing Prosperity, Sydney, Australia, Federation Press, 1998.

28. Sheather, G.D. "Towards and integrated supply chain model II: Shift from sequential supply chain management to supply web partnerships" Proceedings of ANZAM 99: From the Edge - Management and Beyond, Hobart, 1-4 December, 1999.

29. Skoett-Larsen, T. "Supply chain management; A new challenge for researchers and managers in logistics", International Journal of Logistics Management. 10(2): pp 41-53, 1999.

30. Spekman, R. and Sawhney, K. "Toward a Conceptual Understanding of the Antecedents of Strategic Alliances", Business Marketing: An Interaction and Network Perspective, Boston, Kent Publishing, pp 157-192, 1995.

31. STOCHNET Users Manual Version 1.1, E. Zeggelink, P. Boer and T. Snijders, December, 2000.

32. Tan, K.C., Kannan, V.R. and Handfield, R.B. "Supply Chain Management: Supplier Performance and Firm Performance", International Journal of Purchasing and Material Management, August Issue, pp 2-9, 1998.

33. Walton, S.V. and Gupta, N.D. "Electronic Data Interchange for Process Change in an Integrated Supply Chain", International Journal of Operations and Production Management, Vol. 19, No. 4, 1999.

34. Wasserman, S. and Faust, K. Social Network Analysis - Methods and Applications, London, Cambridge Press, 1994.

35. Wisner,J.D. and Tan, K.C. "Supply Chain Management and its impact on purchasing”, Journal of Supply Chain Management. 36(4): pp 33-42, Fall, 2000.

36. Zhang, Z. and Sharifi, H. "A Methodology for Achieving Agility in Manufacturing Organisations", International Journal of Operations and Production Management, Vol. 20, No. 4, 2000. 


\section{Appendix A: Grouping of sites according to multiple/single linkages}

Cluster analysis (based on an inter-firm matrix of the number and utilisation of common suppliers), produced a continuum of ten (10) groups of OEMs, ranging from single (1-3) through to multiple (4-8) product suppliers. Majority of sites purchase from between 1 to 4 first-tier supply firms, a smaller number of Mid range OEMs rely on 5 to 6 suppliers, with the remaining larger OEMs drawing upon 7 to 8 multiple-tier suppliers. The dendogram depicting these ten groupings, with Leader firms identified within each group, is tabled at the oral presentation of the EABR Conference.

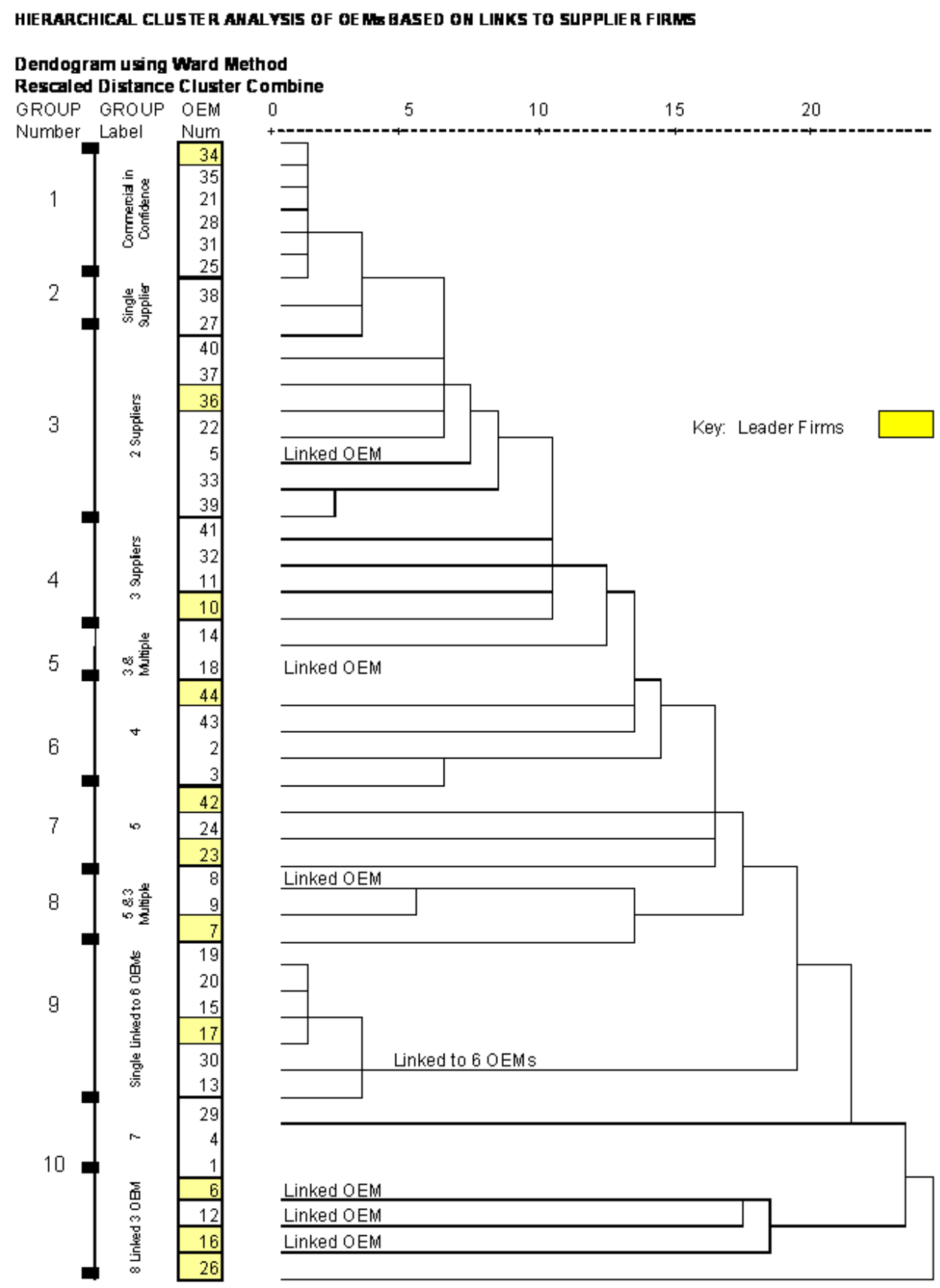




\section{Appendix B: Typology of network types}

NOTE: For each Type, the additional explanation of key agents and descriptive activities is drawn from the Questionnaire responses.

Brokerage-Type A: This occurs where the only link between sites is via a third party, where the potential exists to contact other parties through a 'broker', or 'flexible' or 'formally' organized agents. The ability to negotiate the linkage is to the advantage of the broker exclusively. As a consequence, the broker has the capacity to shape the 'disorganized' others into coherent entities.

Range- Type B: Records a company's access to resources in the larger network - a form of social capital - providing an indication of their power to dominate the network. Achieved via key 'linking agents' operating from within respective networks who form ties to build, bridge and connect to other clusters that can provide valuable resources. This bridging of supply chains occurs through many avenues.

Prominence- Type C: Records the level of demand for a company's products or services as it reflects the power of the enterprise to dominate the marketplace and command a level of industry prestige. It is measured by the company's market share, extent of JIT contracts, use of professional warehousing, and an OEM utilising manytiered and a large number of supply chains. These firms dominate the supply/buy networks through 'preferred supplier' contracts, preferential customer delivery schedules, price control, quality levels, and ISO certification.

Equivalence- Type D: Represents groups of sites that share similar patterns of direct and/or indirect relations with common third parties. For example, two sites are equivalent because they have the same supply/sell chains, share distribution/logistic/transport systems, have the same customer base and product portfolios, share similar target markets, and contract with the same professional and out-sourced services.

Cohesion- Type E: Depicts the ultimate level of integrated network based on strong bonds, cliques and ties, plus common interests and mutuality of objectives. The key is the strength of the communication ties, and the degree the sites are linked to each other via direct contact or mutual programs or joint ventures. In its ultimate form it is a true self-contained 'cluster' model. Membership may be via fully integrated supply networks, industry/regional benchmarking groups, AusIndustry focus groups, strong business network/clusters, joint buyer associations and trade blocks. 
Notes 